\title{
Christmas, wine and Covid-19
}

\author{
Shaun R. McCann $\mathbb{1}^{1}$
}

Received: 16 November 2020 / Revised: 19 November 2020 / Accepted: 23 November 2020 / Published online: 9 December 2020

(c) The Author(s), under exclusive licence to Springer Nature Limited part of Springer Nature 2020

'...Not what they want but what is good for them'

Oliver Cromwell (1599-1658). Lord Protector of the Commonwealth of England, Scotland and Ireland.

What do Oliver Cromwell and Covid-19 have in common? They both seem to share the dubious reputation of cancelling Christmas celebrations. Oliver Cromwell and his fellow Puritans, thought Christmas festivities were sinful, Fig. 1. They viewed the celebration of Christ's birth on the 25th of December as a "popish" tradition derived from the Roman Catholic Church (Christ's Mass), thus threatening their core Christian beliefs. In 1644, an Act of Parliament banned the festival and in June 1647, the Long Parliament (an English Parliament that lasted from 1640 until 1660) passed an ordinance confirming the abolition of the feast of Christmas. Oliver Cromwell was not liked by everybody but especially in Ireland, following a brutal conquest and the introduction of the Penal Laws (Catholics were barred from membership of the Irish Parliament and most had their lands confiscated. Catholic clergy were expelled from Ireland) [1]. From a haematological point of view, it is interesting to observe that Cromwell died from malaria (falciparum presumably).

Christmas was reinstated in England after the Restoration in 1660 and since then has enjoyed popularity in most of the world. In countries that are predominantly Jewish or Muslim, Christmas is still observed as a holiday.

Although originally a religious feast, Christmas has gradually become secularised and commercialised to such an extent it seems to have lost some of its charm and relevance. In the Covid-19 pandemic, it looks as if all Christmas gatherings will be prohibited and it probably will bring to an end the rather dubious 'office party'. The inability of families to come together during this pandemic

Shaun R. McCann

shaunrmccann@gmail.com

1 Haematology Emeritus, University of Dublin Trinity College, Dublin, Ireland

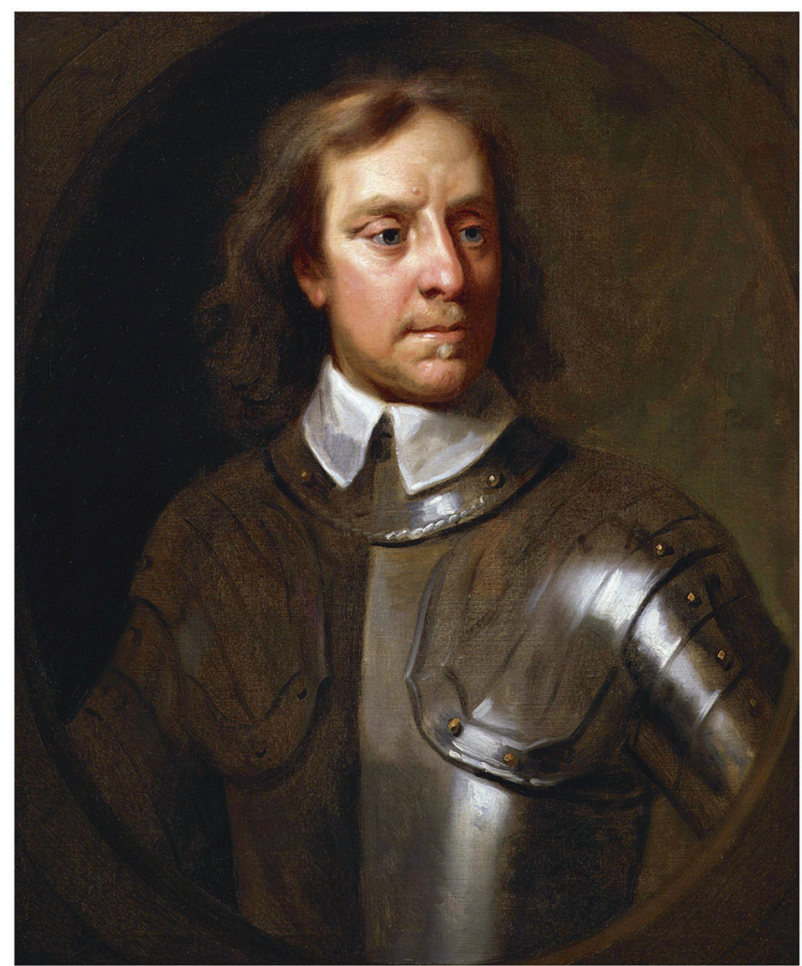

Fig. 1 Oliver Cromwell. Oliver Cromwell was Lord Protector of the Commonwealth of England, Scotland and Ireland.

will be very difficult especially if family members are widely scattered throughout the world.

What about HCT activity around the 25th of December? In discussions with Per Ljungman he tells me that the EBMT have not looked specifically at the issue but he says: 'The Karolinska and all other Swedish centres reduce activity for about 2 weeks also because it is difficult to get unrelated donor harvests performed in the middle of the holiday season'.

I never enjoyed being 'on call' during the Christmas holiday period. Not because I resented being away from my family, but because it was always more difficult to get things done in the hospital during this holiday period. I clearly remember spending a number of hours on Christmas day trying to persuade an HCT recipient, a young woman in 
first remission from AML, from discharging herself from the unit to be with her family even though she had severe acute graft-versus-host disease. Happily, my attempt at persuasion was successful, she survived and as far as I know is still alive and well and free of disease.

Wine shops, off licences and wine societies always increase their sales prior to and during the Christmas holiday season. However, 2020 may be different. We have seen a reduction in champagne sales due to Covid-19 and the high tariff on French wine imported to the United States will presumably add to the problem.

Christmas is a time of gustatory indulgence in most societies and food and wines vary from country to country. In Ireland, the UK and the United States, turkey is still the mainstay of the main course on Christmas day, although goose is increasing in popularity. From my memory of living in the Unites States, 'Thanksgiving' is a bigger feast than Christmas and the consumption of turkey is virtually mandatory. There will probably be a problem this year due to Covid-19. Kim Severson's [2] writing in the New York Times International says that family celebrations will be smaller and this will create a demand for smaller turkeys and the demand for large turkeys may be down by $20 \%$. Time will tell. In France, a family meal, Réveillon de Noël, is de rigueur and commonly includes shell fish, foie-gras, salmon and roast ham and/or turkey, whereas in Italy, although there is geographical variation within the country, pasta, veal, lamb or braised beef are enjoyed. Turkey seldom features. In Germany and Spain, the main gustatory celebration in on Christmas eve when sea food, duck, goose, rabbit are common, but roast turkey is gaining in popularity. In Israel, roast turkey stuffed with pepper, cinnamon and nutmeg is a favourite, but lamb is widely consumed. In Brazil, roast turkey, pork or cod fish are the most popular dishes (personal communication from Júlio Anselmo de Sousa Neto).

What should we drink with all this wonderful food? There is always a debate. Should you imbibe top quality wines or not? I think most people agree that sparkling wine always adds to the enjoyment of the meal. Served as an aperitif or with the first course of smoked salmon or prawns (or other shell fish) it is always acceptable. I prefer my smoked salmon with lemon juice and ground black pepper and traditional brown bread. For those who do not like sparkling wine, then a Chablis, Picpoul de Pinet or a fino sherry or manzanilla are good alternatives.

The discussion becomes more serious when considering what to drink with the main course. Should you reach into your cellar and bring out your finest? I do not think so. A young Cru Beaujolais is fine and for those who prefer white wine, a Chardonnay or white Rioja will be quite acceptable. Arak, Fig. 2, a Lebanese invention, is widely consumed, in

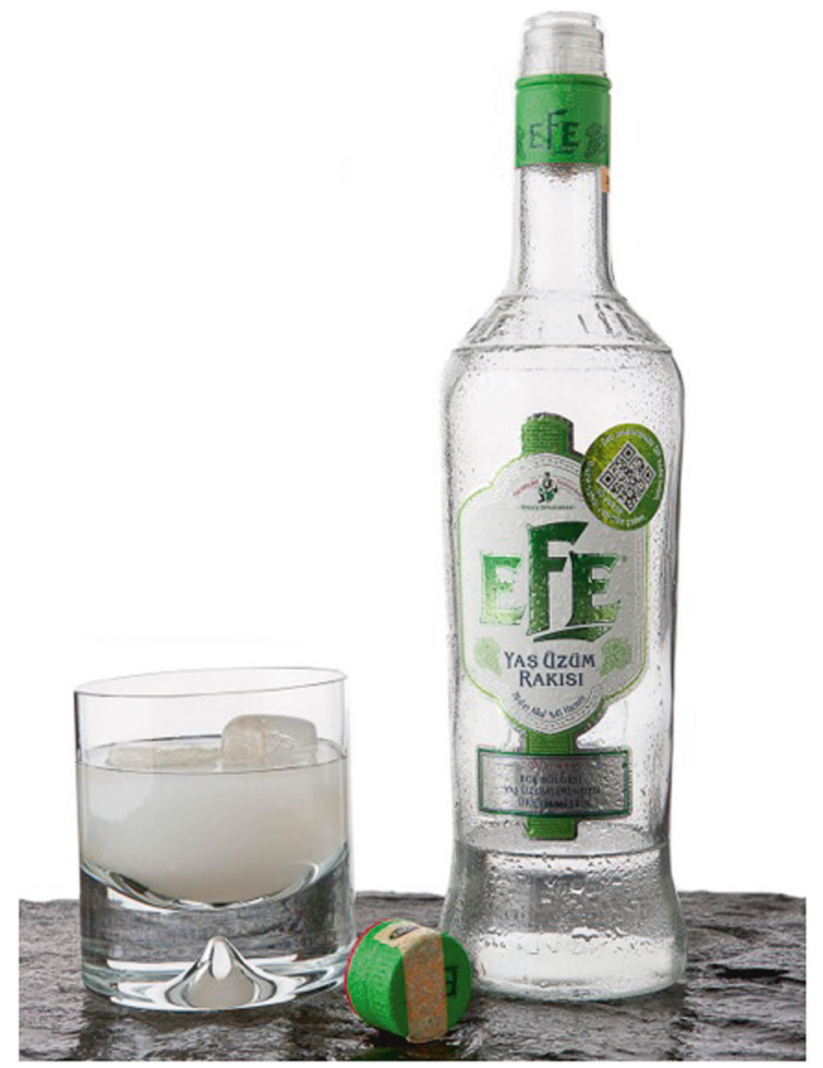

Fig. 2 A bottle of Arak. Arak is a Levantine unsweetened distilled spirit. It has a slight liquorice taste and becomes turbid when water/ice is added. This bottle was a present I received in Turkey at an EHA tutorial.

many iterations, in the Middle East and many Mediterranean countries.

As goose is increasing in popularity, try it with a Gewurztraminer (do not try to spell this after a few glasses of champagne), Pinot Gris or a Riesling. However, the best advice is to drink whatever you like, do not drink too much and do not give in to the temptation of serving your best wines as they may not be appreciated.

Above all enjoy the day and keep your PPIs handy.

\section{Compliance with ethical standards}

Conflict of interest The author declares no conflict of interest.

Publisher's note Springer Nature remains neutral with regard to jurisdictional claims in published maps and institutional affiliations.

\section{References}

1. Morrill JS. Oliver Cromwell. English statesman. https://www.brita nnica.com/biography/Oliver-Cromwell. 2020.

2. Severson K (October 20). Fewer, smaller holiday turkeys? New York Times International. 2020. 